\section{AB0164 THE EFFECT OF RHEUMATOID ARTHRITIS ON FEMALE FERTILITY}

S. Ben Jemaa ${ }^{1}$, G. Mouna2, A. Hriz2, A. Feki2, H. Fourati2, S. Baklouti2. ${ }^{1}$ Hedi Chaker Hospital, Rheumatology, SFAX, Tunisia; ${ }^{1}$ Hedi Chaker Hospital, Rheumatology, SFAX, Tunisia

Background: Infertility is a disease of the reproductive system defined by the failure to achieve clinical pregnancy after 12 months or more of regular unprotected sexual intercourse. Although rheumatoid arthritis (RA) tends to have a late onset, the disease also occurs during child-bearing years and may interfere with procreation.

Objectives: The aim of this study was to compare fertility rates in women with RA with birth-year-matched references from the general population.

Methods: This is a case-control study. Menopausal married women who were diagnosed in the department of Rheumatology at Hedi Chaker Hospital before the age of forty were recruited into this study as cases and apparently healthy age matched married women were recruited as controls. Demographic, clinical, immunological, radiological and therapeutic data were collected from each case using the medical record of patient. Data obtained included age, age of RA onset, duration of RA, extra-articular manifestations, Rheumatoid factor (RF), anti-cyclic citrullinated peptide antibody (ACPA), the presence of erosions on radiographs of hands and feet and the therapy.

Rheumatoid arthritis and controls women were asked to state their menstrual regularity, age at menarche, age at menopause, gestity, parity, number of living children, time to first pregnancy, presence of primary or secondary infertility, the interpregnancy interval, presence of miscarriage or in utero foetal death (IUFD) or preterm delivery and their number.

Results: The mean ages of the cases and controls was $54 \pm 8,11$ years [39, 69]. The median duration since onset of RA in the patients was $22,5 \pm 10,53$ years $[1,47]$. The mean age of onset of the disease was $31,4 \pm 6,3[18,39]$ years. Forty-nine percent $(49 \%)$ of patient had extra-articular manifestations: ocular sicca syndrome in $43,8 \%$ of cases, pulmonary fibrosis in $5,3 \%$ of cases and rheumatoid nodules in $1,8 \%$ of cases. Rheumatoid factor (RF) was present in $61,4 \%$ of cases while anti-CCP anti-body was present in $59,6 \%$ of cases.

Erosive polyarthritis was found in $80,7 \%$ of patients. The mean rate of RF was $319,7 \pm 462,4 \mathrm{UI} / \mathrm{ml}$ and the mean rate of anti-CCP was 185,8 \pm 264 .

Women with RA had a statistically significant mean time to pregnancy longer than the control group. Primary infertility was seen in $15(26,3 \%)$ patients and 2 $(3,5 \%)$ controls, whereas secondary infertility was seen in $31(54,5 \%)$ patients and $2(3,5 \%)$ controls. The patients were significantly more likely to have primary and secondary infertility. There were no significant differences in the age at menarche, the number of children, the gestity and the parity between the two groups. The age at menopause was statistically significant lower in the group patients than controls.

Conclusion: Our study showed that RA women are more likely to have reduced fertility than general population. Although this study cannot definitively address the issue of impaired fertility among women with RA, the results are suggestive enough to warrant further research into the link between RA and fertility that takes women's childbearing choices into account.

\section{REFERENCES:}

[1] Clowse ME, Chakravarty E, Costenbader KH, Chambers C, Michaud K. Effects of infertility, pregnancy loss, and patient concerns on family size of women with rheumatoid arthritis and systemic lupus erythematosus. Arthritis Care Res 2012; 64: 668-74.

[2] Brouwer J, Hazes JM, Laven JS, Dolhain RJ. Fertility in women with rheumatoid arthritis: influence of disease activity and medication. Ann Rheum Dis 2015; 74: 1836-41.

[3] Pope JE, Bellamy N, Stevens A. The lack of associations between rheumatoid arthritis and both nulliparity and infertility. Semin Arthritis Rheum 1999; 28:34250.

[4] Akintayo RO, Aworinde O, Ojo O, Akintayo FC, Akinlade OM, Awodun RO, Isa SO. Is rheumatoid arthritis an innocent bystander in female reproductive problems? A comparative study of fertility in Nigerian women with and without rheumatoid arthritis. Eur J Rheumatol 2018; 5(3): 179-83.

Disclosure of Interests: None declared

DOI: 10.1136/annrheumdis-2021-eular.3055

\section{\begin{tabular}{|l|l}
\hline AB0165 & CENTRAL SENSITIZATION IN RHEUMATOID \\
\hline
\end{tabular} ARTHRITIS}

E. Filatova ${ }^{1}$, E. Pogozheva ${ }^{1}$, V. Amirdzhanova ${ }^{1}$, A. Karateev ${ }^{1}$, A. Lila ${ }^{1}{ }^{1}$ VA Nasonova Research Institute of Rheumatology, Rheumatology, Moscow, Russian Federation

Background: Central Sensitization (CS) is a proposed physiological phenomenon in which dysregulation in the central nervous system causes neuronal dysregulation and hyperexcitability, resulting in hypersensitivity to both noxious and non-noxious stimuli. The term Central Sensitivity Syndrome (CSS) describes a group of medically indistinct (or nonspecific) disorders, such as fibromyalgia (FM) $(1,2)$.

The prevalence of $\mathrm{FM}$ has been estimated at $2-7 \%$ in general population, but $10-30 \%$ patients with several rheumatic diseases fulfill the FM criteria, which suggests that they have not only nociceptive pain, but signs of CS or nocyplastic pain. (3)

Objectives: to identify the signs of central sensitization (CS) in patients with rheumatoid arthritis (RA) with the central sensitization inventory (CSI).

Methods: We examined 43 RA patients (mean age 45.5 [29.0; 53.0] years) with chronic pain. The patients underwent rheumatological examinations; CS was diagnosed using the CSI(4).; inflammation severity (DAS28 index), pain intensity (VAS), affective disorders (HADS), and quality of life (EQ-5D) were assessed.

Results: We recruited 36 women and 7 men, mostly with moderate and high disease activity according to the DAS28 index.

Using the CSI subclinical CS was found in 9 patients (20.9\%), mild in 7 (16.3\%), moderate in $8(18.6 \%)$, severe in $16(37.2 \%)$, and extremely severe sensitization in $3(6.7 \%)$. Thus, $62.5 \%$ of patients with RA had had clinically significant CS (CS>40 points according to the CSI questionnaire).

Patients with the presence of CS were characterized by more severe anxiety (10.0 [7.0; 11.0] vs $5.0[3.0 ; 6.0], p=0.001)$ and lower quality of life $(0.52[-0.02$ $0.52]$ vs 0.52 [0.52; 0.69$], p=0.02$ ).

The CSI tests not only pain but also other diseases associated with CS. Comorbid disorders associated with CS were found in patients with RA: $34.9 \%$ had cognitive impairment, $39.5 \%$ had signs of depression.

Conclusion: Central sensitization was detected in $62.5 \%$ of patients with RA using the CSI questionnaire. CS is associated with anxiety and depression and negatively affects the patients' quality of life. Chronic pain in RA can be of a mixed nature: nociceptive and neoplastic, which must be taken into account in the selection of personalized therapy.

\section{REFERENCES:}

[1] Wolfe F. Fibromyalgianess. Arthritis Rheum. 2009; 61: 715-6.

[2] Martins Rocha T, Pimenta S, Bernardo A, et al. Determinants of non-nociceptive pain in Rheumatoid Arthritis. Acta Reumatol Port. 2018 Oct-Dec;43(4):291-303

[3] Halioglu S, Carlioglu A., Akdeniz D., Karaaslan Y., Kosar A. Fibromyalgia in patients user rheumatic patients with several rheumatic diseases: prevalence and relationship with disease activity. Reumatol. Int. 2014 Sep; 34(90:1275-80 doi:10.1007/s00296-014-2972.

Disclosure of Interests: None declared

DOI: 10.1136/annrheumdis-2021-eular.3074

\section{AB0166 MORTALITY AND COMORBIDITIES IN A COHORT OF PACIENTS WITH ESTABLISHED RHEUMATOID ARTHRITIS}

J. Calvo Gutierrez ${ }^{1}$, B. Rodríguez Jiménez ${ }^{2}$, M. L. Ladehesa Pineda ${ }^{1}$, M. RojasGiménez 1 , R. Ortega Castro ${ }^{1}$, A. Escudero Contreras ${ }^{1} .{ }^{1}$ Reina Sofía University Hospital, Maimónides Institute of Biomedical Research of Córdoba (IMIBIC), Rheumatology, Córdoba, Spain; ${ }^{2}$ Reina Sofia University Hospital, Medicine University of Cordoba, Medicine, Córdoba, Spain

Background: Patients diagnosed with Rheumatoid Arthritis (RA) have an increased risk of comorbidities and secondary mortality, in a large extent due to cardiovascular events.

Objectives: To identify the frequency of comorbidity, mortality and variables related to its increase in a cohort of patients with rheumatoid arthritis established (RAE).

Methods: Controlled cross-sectional observational study of a cohort of 188 patients with RAE a 10 year follow-up (5 years if not complete this period).

Results: $62.8 \%$ were women, mean age of patients at the time of inclusion was high $73.3(+/-13.8)$ years and mean duration of disease was $12,8(+/-$ 6,99 ) years. Regarding CV risk factors, $26.6 \%$ smoked, $60.6 \%$ hypertension and $52.1 \%$ diabetic. Regarding comorbidities, the most frequent were serious infections (45.2\%), CVD (35.1\%), Osteoporosis (31.9\%), Depression $(31.9 \%)$ and Kidney disease (26.6\%). During follow-up, an improvement was observed inflammatory parameters and activity levels $(p<0.001)$ Table 1 . Mortality was associated to CVD and severe infection, and depression to lower mortality ( $\mathrm{p}$ 0.05). Overall mortality was $32.4 \%$. A logistic regression was performed in the group of patients with time greater evolution 10 years of our cohort, to be able to better represent the influence of disease carrying with her for longer whose results are shown in Table 2. Analysand survival, men, CVD, severe infections, and Positive Rheumatoid Factor were associated with higher mortality, while treatment with Methotrexate was associated with increased 
survival. Among the causes of death, the most frequent were infections, CVD and solid cancer.

Conclusion: -The incidence of comorbidities in our cohort is similar to that described in the literature.

-Relationship between mortality and CVD and severe infection is demonstrated. -The mortality rate observed is higher than that described in the literature, which be influenced by the advanced age of the patients in the cohort and high time evolution of RA.

REFERENCES:

[1] Lee YK, Ahn GY, Lee J, Shin JM, Lee TH, Park DJ, Song YJ, Kim MK, Bae SC. Excess mortality persists in patients with rheumatoid arthritis. Int J Rheum Dis. 2021 Jan 19. doi: 10.1111/1756-185X.14058. Epub ahead of print. PMID: 33463890.

[2] Mikuls, T. R. (2003). Co-morbidity in rheumatoid arthritis. Best Practice \& Research Clinical Rheumatology, 17(5), 729-752.

[3] Naz, S. M., \& Symmons, D. P. M. (2007). Mortality in established rheumatoid arthritis. Best Practice \& Research Clinical Rheumatology, 21(5), 871-883.

Table 1. Student's t test for paired data.

\begin{tabular}{llll}
\hline Variables & Basal & 10 year & P \\
\hline DAS28 & $5,25(15,08)$ & $2,89(1,06)$ & 0,036 \\
VAS & $38,61(36,45)$ & $26,93(24,97)$ & $<0,001$ \\
HAQ & $1,04(0,79)$ & $0,88(0,87)$ & NS \\
TJC & $4,96(5,38)$ & $1,40(2,57)$ & $<0,001$ \\
SJC & $3,55(3,69)$ & $0,72(2,11)$ & $<0,001$ \\
ESR (mm/h) & $31,47(21,19)$ & $25,86(18,47)$ & $<0,001$ \\
CRP $(\mathbf{m g} / \mathbf{L})$ & $15,24(16,13)$ & $9,41(21,02)$ & 0,001 \\
Hemoglobin $(\mathbf{m g} / \mathbf{d L})$ & $13,44(7,92)$ & $13,52(7,64)$ & NS \\
Glucose $(\mathbf{m g} / \mathbf{d L})$ & $102,26(35,97)$ & $103,83(37,98)$ & NS \\
Cholesterol $(\mathbf{m g} / \mathbf{d L})$ & $203,56(46,11)$ & $195,65(38,12)$ & 0,042 \\
LDL $(\mathbf{m g} / \mathbf{d L})$ & $123,91(40,69)$ & $119,58(33,89)$ & NS \\
HDL $(\mathbf{m g} / \mathbf{d L})$ & $56,73(19,07)$ & $54,84(20,38)$ & NS \\
Triglycerides (mg/dL) & $110,85(60,77)$ & $113,44(55,61)$ & NS \\
\hline
\end{tabular}

Table 2. Logistic regression model. Hosmer-Lemeshow Chi square 9.035 GI 7 p 0.25. Likelihood ratio test Chi square 64.658 GI 5 p $<0.001$. NS, Not significant.

\begin{tabular}{lllll}
\hline Variable & Univariate analysis & $\mathbf{p}$ & Multiivariate analysis & $\mathbf{P}$ \\
& OR (IC 95\%) & & FINAL MODELO & \\
& & & & \\
& & & OR (IC 95\%) & \\
& & & & \\
\hline Dyslipidemia & $1,02(0,47-2,23)$ & 0,965 & & \\
HT & $4,73(1,79-12,48)$ & 0,002 & & \\
DM & $1,42(0,59-3,44)$ & 0,438 & & \\
CV disease & $11,25(4,45-28,44)$ & $<0,001$ & $12,33(3.89-39,04)$ & \\
Hyperuricemia & $3,27(1,39-7,65)$ & 0,006 & & 0,015 \\
Thyroid disease & $0,56(0,15-2,11)$ & 0,393 & & 0,014 \\
Interstitial lung disease & $2,48(0,77-7,99)$ & 0,127 & $7,37(1,48-36,84)$ & \\
Osteoporosis & $2,38(1,07-5,29)$ & 0,033 & & \\
Renal disease & $8,25(3,41-19,97)$ & $<0,001$ & $4,14(1,34-12,80)$ & \\
Depressión & $0,32(0,12-0,84)$ & 0,021 & $0,20(0,06-0,74)$ & \\
Solyd CA & $1,12(0,44-2,87)$ & 0,809 & & \\
Hematologic CA & $<0,001(\mathrm{NS})$ & 0,999 & & \\
Amyloidosis & $2,65(0,16-43,52)$ & 0,496 & & \\
Severe infecction & $6,22(2,53-15,29)$ & $<0,001$ & $5,59(1,66-18,79)$ & 0,005 \\
COVID-19 infection & $1,31(0,12-14,91)$ & 0,828 & & \\
& & & & \\
\end{tabular}

Disclosure of Interests: None declared

DOI: 10.1136/annrheumdis-2021-eular.3082

\section{AB0167 PECULIARITIES OF INTERACTION OF CHRONIC INFLAMMATION AND DEPRESSION IN RHEUMATOID ARTHRITIS}

A. Aleksandrov ${ }^{1}$, N. Aleksandrova ${ }^{1} .{ }^{1}$ Federal State Budgetary Institution «Research Institute of Clinical and Experimental Rheumatology named after A.B. Zborovsky», Department of Clinical and Laboratory Diagnostics, Volgograd, Russian Federation

Background: In patients with rheumatoid arthritis (RA), a high prevalence of depression and anxiety is observed, and the severity of these conditions depends on the degree of vitamin $D$ deficiency. The role of the main mediator, with the help of which psychological and physical stress factors can contribute to the development of depression and systemic diseases, has been attributed to inflammation in recent years.
Objectives: to assess the dependence of depressive disorders on vitamin D deficiency and the level of pro-inflammatory cytokines in patients with RA.

Methods: 88 women with a reliable diagnosis of RA (mean age $54.2 \pm 12.0$ years old, disease duration $9.0[3.5 ; 16.0]$ years) were under observation. Beck's depression inventory (BDI-II) was used to assess the presence of depressive symptoms. ELISA test was used to measure serum cytokines (IL-1, IL-6) and serum 25(OH)D levels.

Results: The presence of depression was found in $66 \%$ of patients with RA. An insufficient level of $25(\mathrm{OH}) \mathrm{D}(<30 \mathrm{ng} / \mathrm{ml})$ was determined in $89.8 \%$ of cases. In RA patients with no signs of depression, the level of $25(\mathrm{OH}) \mathrm{D}$ showed maximum values and significantly differed from that in the groups of patients with moderate $(p=0.028)$ and severe depression $(p<0.001)$. A negative correlation $(r=-0.38$ $n=88, p<0.05)$ was established between the level of $25(\mathrm{OH}) \mathrm{D}$ and the sever ity of depression. A positive relationship was also found between 25(OH)D and ESR $(r=0.29, n=73, p<0.05)$ and a negative relationship with the number of painful joints $(r=-0.29, n=76, p<0.05)$. Probably, vitamin $D$ is indirectly involved in inflammatory processes in joints and in central sensitization, which provokes chronic pain and psychological disorders in patients with RA.

The level of IL- 6 in patients with RA with moderate and severe depression $(n=18$ $14.6 \pm 6.7 \mathrm{pg} / \mathrm{ml}$ ) significantly exceeded the parameters of patients with RA without depressive disorders $(n=30 ; 9.8 \pm 3.7 ; p=0.003)$. There was also a tendency to increase IL- 6 in the group of patients with moderate and severe depression compared with patients with mild depression $(p=0.06)$. IL-1 $\beta$ values significantly increased with the progression of depression (without depression - mild depression, $p=0.034$; mild - moderate, $p<0.001$; moderate - severe depression, $p$ $=0.044)$. A positive correlation of average severity was revealed between the degree of depression (according to BDI-II) and the dose of glucocorticoids (GC) at the time of the study $(r=0.33, p=0.002)$. An increase in the $G C$ dose in the short term can aggravate depressive disorders in RA patients (Table 1).

Table 1. Indicators of levels of depression and IL-1 $\beta$ depending on the dose of GC

\begin{tabular}{|c|c|c|c|}
\hline & $\begin{array}{l}\text { Group I }(n=26) \text {, } \\
\text { without } G C\end{array}$ & $\begin{array}{l}\text { Group II }(\mathrm{n}=45) \text {, } \\
\mathrm{GC}<10 \mathrm{mg} / \text { day }\end{array}$ & $\begin{array}{l}\text { Group III } \\
(\mathrm{n}=17) \\
\mathrm{GC} \geq 10 \mathrm{mg} \\
/ \text { day }\end{array}$ \\
\hline $\begin{array}{l}\text { Depression level according to BDI-II, } \\
\text { points (Me [P25; P75]) }\end{array}$ & $8,5[5 ; 16]$ & $14[9 ; 17]$ & $19[14 ; 29]^{*}{ }^{* \mid I-I}$ \\
\hline IL-1 $\beta$ level, $\mathrm{pg} / \mathrm{ml}(\mathrm{M} \pm \mathrm{SD})$ & $4,57 \pm 1,83^{*|-| I}$ & $6,04 \pm 3,27$ & $6,52 \pm 5,16$ \\
\hline
\end{tabular}

* - intergroup differences are reliable, $p<0.05$

Patients who used GC in a daily dose of $\geq 10 \mathrm{mg} /$ day (group III) had a higher degree of depression compared to patients with RA from group I ( $z=-2.98 ; p=$ $0.003)$. In patients with RA in the first group, the level of IL-1 $\beta$ was significantly higher $\left(p_{1-||}=0.039\right)$ than in patients with GC prescription in minimal doses (up to $10 \mathrm{mg} /$ day) (Table 1). Glucocorticoid hormones suppress pro-inflammatory cytokines. As a rule, this effect is not observed in patients with depression. This fact may indicate a violation of homeostatic mechanisms. IL-1 $\beta$ is thought to be the first step in the pro-inflammatory response to psychological stress and is capable of inducing a subsequent cascade of other inflammatory cytokine responses.

Conclusion: Restoring the normal level of $25(\mathrm{OH}) \mathrm{D}$ in the blood serum of patients with RA can positively affect psychological indicators by reducing the severity of depression and manifestations of pain. The activation of pro-inflammatory cytokines during stress and depression suggests that suppression of the inflammatory response can also reduce the symptoms of depression in RA patients.

Disclosure of Interests: None declared

DOI: 10.1136/annrheumdis-2021-eular.3087

\section{$\mathrm{AB} 0168$ \\ BODY MASS INDEX IS ASSOCIATED WITH SIGNIFICANT ECHOCARDIOGRAPHIC ABNORMALITIES IN RHEUMATOID ARTHRITIS}

S. Hannawi ${ }^{1}$, K. Naeem ${ }^{2}, \underline{\mathrm{H}}$. Hannawi ${ }^{3} .{ }^{1}$ Ministry of Health and PreventionUAE, Rheumatology, Dubai, United Arab Emirates; ${ }^{2}$ Ministry of Health and Prevention-UAE, Internal Medicine, Dubai, United Arab Emirates; ${ }^{3}$ Ministry of Health and Prevention-UAE, Research, Dubai, United Arab Emirates

Background: Overweight/obesity is associated with a high incidence of chronic autoimmune diseases such as rheumatoid arthritis (RA). In RA, obesity represents an increasingly prevalent comorbidity even at its first presentation, with more than $60 \%$ of patients with RA classified as overweight or obese by the body mass index $\left(B M I \geq 25 \mathrm{~kg} / \mathrm{m}^{2}\right)$. On the other hand, $R A$ is related with excess 